\title{
AUTHOR INDEX \\ VOLUME 5 (1997)
}

Anvari, M., see Bloch, I.

Bloch, I., Maitre, H. and Anvari, M., Fuzzy adjacency between image objects

Bortolan, G. and Pedrycz, W., Fuzzy encoding and decoding:

A Study in information granularity

5 (1997) 615

5 (1997) 615

5 (1997) 71

Chang, M.M.Y., see Liu, J.

5 (1997) 13

Chem, W.K., see Liu, J.

Chen, C.-B. and Wei, C.-C., An approach for solving fuzzy MADM problems

de Mantaras, R.L. and Godo, L., From intervals to fuzzy truth-values: Adding flexibility to reasoning under uncertainty

Dubois, D. and Prade, H., Fuzzy sets and fuzzy logic - theory and applications, by G. J. Klir and B. Yuan

Dujet, C., see Vincent, N.

Estrakh, D.D., see Mitchell, H.B.

Estrakh, D.D., see Mitchell, H.B.

Fan, T. and Ralescu, D.A., On the comparisons of OWA operators and ordinal OWA operators

Fedrizzi, M., see Novák, V.

Fodor, J.C., Yager, R.R. and Rybalov, A., Structure of uninorms

Fujimoto, K. and Murofushi, T., Some characterizations of the systems represented by choquet and multi-linear functionals through the use of Möbius inversion

Fujimoto, K., see Murofushi, T.

Gao, W.Z., see Wang, J.

Gehrke, M., Walker, C. and Walker, E., A mathematical setting for fuzzy logics

Godo, L., see de Mantaras, R.L.

$5(1997) 13$

5 (1997) 459

5 (1997) 251

5 (1997) 505

5 (1997) 93

5 (1997) 429

5 (1997) 689

5 (1997) 1

5 (1997) 31

5 (1997) 411

5 (1997) 547

5 (1997) 563

5 (1997) 139

5 (1997) 223

5 (1997) 251

Grabisch, M., Alternative representations of discrete fuzzy measures for decision making

5 (1997) 587

5 (1997) 515

Grabisch, M., Preface

Gupta, M.M., Fuzzy sets, fuzzy logic, and fuzzy systems - selected papers by Lotfi A. Zadeh, ed. G.J. Klir and B. Yuan

Gwét, H., Normalized conditional possibility distributions and informational connection between fuzzy variables 
Hüllermeier, E., An approach to modelling and simulation of uncertain dynamical systems

5 (1997) 117

Harding, J., Marinacci, M., Nguyen, N.T. and Wang, T., Local radon-Nikodym derivatives of set functions

Imaoka, $\mathrm{H}$., On a subjective model by a generalized fuzzy integral

5 (1997) 379

5 (1997) 517

5 (1997) 239

Jamison, K.D., see Lodwick, W.A.

Kambara, H., see Matsushita, Y.

Klir, G.J., see Wang, Z.

Kreinovich, V., see Nguyen, H.T.

Kreinovich, V., Guest editors' introduction: Interval methods in representing and processing uncertainty

Kreinovich, V., Interval methods in knowledge representation (abstracts of recent papers)

Kreinovich, V., Interval methods in knowledge representation (abstracts of recent papers)

Kreinovich, V., Interval methods in knowledge representation (abstracts of recent papers)

5 (1997) 531

5 (1997) 163

5 (1997) 317

5 (1997) 221

5 (1997) 107

5 (1997) 213

5 (1997) 395

Kreinovich, V., Interval methods in knowledge representation (abstracts of recent papers)

Kreinovich, V., Interval methods in knowledge representation (abstracts of recent papers)

5 (1997) 509

5 (1997) 609

Kreinovich, V., Interval methods in knowledge representation (abstracts of recent papers)

Larson, P.-A., see Zhu, Q.

Li, M.Z., see Wang, J.

Liu, J., Cham, W.K. and Chang, M.M.Y., On-line chinese character recognition by incorporating human knowledge

Liu, W.J. and Sugeno, M., Inducing a membership function of a category in a fuzzy-set-based attribute space

Lodwick, W.A. and Jamison, K.D., Interval methods and fuzzy optimization

Maitre, H., see Bloch, I.

Malik, D.S., Mordeson, J.N. and Sen, M.K., Admissible partitions of fuzzy finite state machines

5 (1997) 733

5 (1997) 701

5 (1997) 47

5 (1997) 13

5 (1997) 147

5 (1997) 239

5 (1997) 615

5 (1997) 723

5 (1997) 379

Marinacci, M., see Harding, J.

Matsushita, Y. and Kambara, H., Partition type fuzzy integral model for evaluation process

Matsushita, Y. and Kambara, H., Partition type fuzzy integral model for evaluation process (Errata)

5 (1997) 531

5 (1997) 735

5 (1997) 401

5 (1997) 655

Merdan, O., see Yazici, A.

Mitchell, H.B. and Estrakh, D.D., A fuzzy switched DPCM predictor for lossless compression of noisy images

5 (1997) 689

Mitchell, H.B. and Estrakh, D.D., A modified OWA operator and its use in lossless DPCM image compression

5 (1997) 429

5 (1997) 723

Mordeson, J.N., see Malik, D.S.

Mouaddib, N. and Subtil, P., Management of uncertainty and vagueness in databases: The firms point of view

Murofushi, T., see Fujimoto, $\mathrm{K}$. 
Murofushi, T., Sugeno, M. and Fujimoto, K., Separated hierarchical decomposition of the choquet integral

$\mathrm{Ng}, \mathrm{R} . \mathrm{T}$., Reasoning with uncertainty in deductive databases and logic programs

Nguyen, H.T., Kreinovich, V. and Zuo, Q., Interval-valued degrees of belief: Applications of interval computations to expert systems and intelligent control

5 (1997) 563

5 (1997) 261

Nguyen, H.T., Nguyen, N.T. and Wang, T., On capacity functionals in interval probabilities

5 (1997) 317

5 (1997) 359

5 (1997) 379

Nguyen, N.T., see Harding, J.

Nguyen, N.T., see Nguyen, H.T.

Novák, V., Zorat, A. and Fedrizzi, M., A simple procedure for pattern pre-recognition based on fuzzy logic analysis

Pedrycz, W., see Bortolan, G.

Prade, H., see Dubois, D.

Ralescu, D.A., see Fan, T.

Rybalov, A., see Fodor, J.C.

Sen, M.K., see Malik, D.S.

Sgarro, A., Bodies of evidence versus simple interval probabilities

Subrahmanyam, P.V. and Sudarsanam, S.K., On the integrable solution of a class of fuzzy functional equations

Subtil, P., see Mouaddib, N.

Sudarsanam, S.K., see Subrahmanyam, P.V.

Sugeno, M., see Liu, W.J.

Sugeno, M., see Murofushi, T.

Torrens, J., see Mayor, G.

Toth, H., Fuzziness: From epistemic considerations to terminological clarification

Vincent, N. and Dujet, C., A suggested conditional modus ponens

Walker, C., see Gehrke, M.

Walker, E., see Gehrke, M.

Wang, F.L., see Wang, J.

Wang, J. and Gao, W.Z., Adaptive pole placement control algorithm for nonlinear systems

Wang, J., Wang, F.L., Li, M.Z. and Yang, Y.H., A knowledge-based controller used in process control systems

Wang, T., see Harding, J.

Wang, T., see Nguyen, H.T.

5 (1997) 359

5 (1997) 31

5 (1997) 71

5 (1997) 505

5 (1997) 1

5 (1997) 411

5 (1997) 723

5 (1997) 199

5 (1997) 59

5 (1997) 437

5 (1997) 59

5 (1997) 147

5 (1997) 563

5 (1997) 401

5 (1997) 481

5 (1997) 93

5 (1997) 223

5 (1997) 223

5 (1997) 47

$5(1997) 139$

5 (1997) 47

5 (1997) 379

5 (1997) 359

Wang, Z. and Klir, G.J., PFB-integrals and PFA-integrals with respect to monotone set functions

5 (1997) 163

5 (1997) 459

Wygralak, M., On the best scalar approximation of cardinality of a fuzzy set

Yager, R.R., see Fodor, J.C.

Yang, Y.H., see Wang, J.

Yazici, A. and Merdan, O., Verification and transformation of complex and uncertain conceptual schemas

5 (1997) 681

5 (1997) 411

5 (1997) 47

5 (1997) 655

Zhu, Q. and Larson, P.-A., A fuzzy query optimization approach for multidatabase systems

Zorat, A., see Novák, V.

5 (1997) 701

5 (1997) 31

Zuo, Q., see Nguyen, H.T.

5 (1997) 317 